\title{
OEXLE, Otto Gerhard, Stand und Perspektiven der Mittelalterforschung am Ende des 20. Jahrhunderts
}

\section{Étienne Champion}

\section{OpenEdition}

\section{Journals}

Édition électronique

URL : http://journals.openedition.org/ifha/1513

DOI : 10.4000/ifha.1513

ISSN : 2198-8943

Éditeur

IFRA - Institut franco-allemand (sciences historiques et sociales)

Référence électronique

Étienne Champion, «OEXLE, Otto Gerhard, Stand und Perspektiven der Mittelalterforschung am Ende des 20. Jahrhunderts », Revue de l'IFHA [En ligne], Date de recension, mis en ligne le 01 janvier 1997, consulté le 22 septembre 2020. URL : http://journals.openedition.org/ifha/1513 ; DOI : https://doi.org/ 10.4000/ifha. 1513

Ce document a été généré automatiquement le 22 septembre 2020.

(C)IFHA 


\title{
OEXLE, Otto Gerhard, Stand und Perspektiven der Mittelalterforschung am Ende des 20. Jahrhunderts
}

\author{
Étienne Champion
}

1 Les Göttinger Gespräche zur Geschichtswissenschaft réunissent régulièrement, au sein du Max-Planck-Institut für Geschichte de Göttingen, deux ou trois spécialistes allemands et étrangers pour débattre des grandes questions méthodologiques et historiographiques actuelles. La maison Wallstein édite ainsi la seconde série de conférences, cette fois consacrée à un bilan et aux perspectives de l'histoire médiévale à la fin du XXe s.

2 A.E. estime que si les divergences entre historiographies nationales (notamment entre historiographie française et allemande) s'estompent, elles perdurent encore, bien que ces différences soient peut-être avant tout le résultat d'un discours. Ainsi l'opposition entre la réflexion méthodologique plus »allemande« et la problématisation plus "française« est-elle assez artificielle: en Allemagne, on entend souvent problématique là où l'on parle de méthode. A.E. souligne l'importance de la dimension internationale mais aussi interdisciplinaire de la recherche médiévale. Il défend avec ardeur les instituts, en tant que structures, qui, n'étant pas contraints par les mêmes obligations que les universités, ont un rôle complémentaire et irremplaçable à jouer, notamment dans le cadre de projets de longue durée pouvant réunir de nombreux chercheurs d'horizons très divers. Dans ce cadre, les problématiques portant sur les sources doivent être privilégiées par rapport aux interrogations purement théoriques, car elles sont l'instrument d'une histoire "globale" (mais peut-on envisager une autre histoire, souligne A.E.) qui doit être présente dans les livres et les colloques mais aussi dans l'esprit de chacun.

3 J.F. place sa réflexion dans la longue durée puisqu'il analyse l'évolution de l'historiographie depuis le XIXe s., soulignant l'importance toujours réaffirmée des sources et de leur critique, insistant sur le fait que cet attachement n'est en aucune manière incompatible avec une évolution moderne de l'histoire. Au XIXe s., la réflexion 
se posait en terme de document "vrai« ou »faux«, au début du XXe s., la question de la vérité s'est appliquée au "contenu" du document. La critique moderne, tout en assimilant les apports de ses prédécesseurs, les intègre dans une analyse plus globale où le vrai et le faux n'ont plus de valeur absolue: la complexité croissante du traitement des sources est en totale adéquation avec la complexité croissante des problématiques historiques. Le titre de la conférence, »de l'émiettement à la réunification" plaide pour une nouvelle histoire globale qui, profitant de la diversité des approches qu'a connue la discipline, permet d'envisager un nouvel humanisme. L'héritage quantitatif, l'apport de l'informatique, utilisés d'abord par l'histoire économique et sociale, repris par l'histoire sociale au sens plein du terme, et d'une manière plus générale les interactions entre les différentes tendances historiographiques permettent d'avancer dans le sens de cette nouvelle histoire dont l'étude de la memoria apparaît comme un précurseur.

4 La perspective "américaine« de P.G. est très différente qui présente une analyse quantitative des historiographies allemandes, américaine et française à partir des dépouillements de l'Historische Zeitschrift, de l'American Historical Review et de la Revue Historique. Il souligne que des différences sont encore très perceptibles entre les historiographies. La France serait très tournée vers elle-même, nettement plus que l'Allemagne. L'étude des différentes périodes du Moyen Age montre l'importance du haut Moyen Age en Allemagne, très peu présent en France et aux États-Unis. Mais finalement, ces différences sont fécondes, observe P.G, soulignant l'importance de la "confrontation « scientifique franco-allemande et les progrès qu'elle a pu engendrés. On aura d'ailleurs noté que ce thème est commun aux trois intervenants. 